\title{
A-000 \\ Use of a new enrichment nanosorbent for speciation of mercury by FI-CV-ICP-MS
}

\author{
I. Sánchez Trujillo, E. Vereda Alonso, J.M. Cano Pavón, A. García de Torres \\ Department of Analytical Chemistry, Faculty of Sciences, University of Málaga, Campus de \\ Teatinos, 29071, Málaga, e-mail: jm_cano@uma.es
}

\begin{abstract}
Mercury is one of the most toxic environmental pollutants and its effects on human and ecosystem health are well known. All mercury species are toxic, with organic mercury compounds generally being more toxic than inorganic species. Chromatography techniques (GC, HPLC) coupled to element specific detectors, are able to separate mercury species in order to elucidate mercury transformation and transport processes where the determination of all mercury species is desirable. However, in practice, especially in sampling campaigns for sea water analysis where a large number of samples are collected over a longer period of time, a combination of methods is usually applied to accurately determine the most toxic mercury species. These include non-chromatographic methods based on the different chemical and/or physical behavior of the mercury species. These non-chromatographic methods can be less time consuming, more cost effective and available, and present competitive limits of detection. Especially when mercury could vapor (CV) generation technique is employed, which reduces salt effect on the analytical signal and improve the sensibility. Among non-chromatographic methods, solid phase extraction and microextraction (SPE and SPME) which is becoming increasingly popular for sample preparation in organic analysis, found its way to speciation analysis of organometals. SPE/SPME is the most popular sample preconcentration method for its simplicity, high enrichment factor, low or no consumption of organic solvents and feasibly to be automated. On the other hand, the exploration of new materials, especially nanometer sized materials, as the support phase is another active research area in SPE/SPME for mercury determination. The use of nanoparticles leads to higher extraction capacity/efficiency and rapid dynamics of extraction originated from the higher surface area to volume ratio and short diffusion route.
\end{abstract}

In this work, a new enrichment nanosorbent functionalized with 1,5 bis (2-pyridyl) methylene thiocarbohidrazide was synthesized and characterized. From the study of its adsorption capacity toward metal ions, $\mathrm{Hg}^{2+}$ was observed to be one of the most retained 173.1 $\mu \mathrm{mol} \mathrm{g}{ }^{-1}$ at $\mathrm{pH}$ 5. Thus, a flow injection solid phase extraction and cold vapor generation method for its determination and speciation based on the use of this new chelating nanosorbent was optimized. The method developed has showed to be useful for the automatic pre-concentration and sequential speciation of mercury and methylmercury in environmental and biological samples. The system was based on chelating retention of the analytes onto a mini-column filled with the new nanosorbent and their sequential elution by using two different eluents, $0.2 \% \mathrm{HCl}$ for $\mathrm{CH}_{3} \mathrm{Hg}^{+}$and $0.1 \%$ thiourea in $0.5 \% \mathrm{HCl}$ for $\mathrm{Hg}^{2+}$. The determination was performed using inductively coupled plasma mass spectrometry. Under the optimum conditions and $120 \mathrm{~s}$ preconcentration time, the enrichment factors were 4.7 and 11.0; the detection limits $(3 \sigma)$ were 0.002 and $0.004 \mathrm{~m} \mathrm{~L} \mathrm{~L}^{-1}$; the determination limits $(10 \sigma)$ were 0.011 and $0.024 \mathrm{\mu g} \mathrm{L}^{-1}$; and the precisions (calculated for 10 replicate determinations at a $2 \mu \mathrm{g} \mathrm{L}-1$ standard of both species) were 2.8 and $2.6 \%$ (RSD); for $\mathrm{CH}_{3} \mathrm{Hg}^{+}$and $\mathrm{Hg}^{2+}$, respectively. Linear calibration graphs were obtained for both species from the determination limits to at least $70 \mu \mathrm{g} \mathrm{L}^{-1}$. For the quality control of the analytical performance and the validation of the newly developed method, the analysis of two certified samples, LGC 6016 estuarine water and SRM 2976 mussel tissue were addressed. The results showed good agreement with the certified values. The method was successfully applied to the speciation of mercury in sea-water samples collected in the Málaga Bay. 